\title{
Geotechnical properties of the Belfast estuarine deposits
}

\author{
CROOKS, J. H. A. \& GRAHAM, J. (1976). Géotechnique 26, No. 2, 293-315.
}

\section{S. Leroueil and F. Tavenas, Department of Civil Engineering, Laval University, Quebec City, Canada}

Numerous papers dealing with one aspect or another of the behaviour of natural clays can be found in the literature, but it is seldom possible to evaluate the interrelation between these various aspects and to obtain an overall picture of the behaviour of such soils because of the lack of published data on comprehensive studies. Crooks and Graham must be commended for having carried out such an investigation on the Belfast estuarine clays and for the detailed presentation of their results, particularly with respect to the yield behaviour of these clays. The addition to the literature of these data, on a clay which has not been publicized as much as the Scandinavian or the Canadian clays, will certainly help in establishing a better understanding of the behaviour of natural clays by allowing comparisons of clays of different origin and location. In this sense, the publication of the yield envelopes of the Holywood and Kinnegar clays should be extremely useful, and it is the purpose of this discussion to examine how these envelopes compare to similar data already available.

\section{SHAPE OF THE YIELD ENVELOPES OF THE IIOLYWOOD AND KINNEGAR CLAYS}

The envelopes of the yield points obtained by Crooks and Graham from drained tests following a variety of stress paths are presented in Figs 14 and 15 of the Paper. For shear stresses less than those found in situ, the results presented suggest that the yield envelopes do not cross the isotropic line. In other words, based on the results of tests C-15 for Holywood and D-15 and D-16 for Kinnegar, any isotropic stress condition, including that corresponding to the post-sampling stresses would be outside the yield envelope and would thus correspond to a normally consolidated condition. If this were true, any sample of these clays would necessarily be remoulded. Such characteristics are questionable in as much as they are contrary to all available data on the yielding of natural clays, for which a well defined yield pressure exists in isotropic condition. Moreover, the analysis of the CIU test results presented in Fig. 17 and Tables 2 and 4 of the Paper indicate that the two clays investigated behave as overconsolidated materials up to isotropic consolidation pressures of the order of 40 to $45 \mathrm{kPa}$. This implies that an isotropic yield point exists at or above these values of the isotropic pressure, so that the overall shape of the yield envelopes would be somewhat different from that presented in Figs 14 and 15. It would indeed be useful if the Authors could provide the data on the consolidation stages of their CIU tests to allow a direct determination of the corresponding yield points.

The conflicting indications on the position of the yield envelopes may come from the method used by the Authors to determine the yield points in their different tests: various definitions of yielding had to be used depending on the type stress path followed, and tests C-15, D-15 and D-16 were interpreted from axial or lateral strains against axial or lateral stress plots. It is then logical that the resulting yield points do not agree with those determined from volumetric strains against octahedral normal stress plots, since, as shown by Roscoe and Burland (1968), the volumetric yield does not coincide in general with the limit of shear distortion. 


\section{COMPARISON WITH THE YIELD ENVELOPES OF THE ST ALBAN CLAY}

In the course of a comprehensive investigation on the properties of the clay at a test site in St Alban, Quebec, we have obtained the volumetric yield envelopes on undisturbed samples from two depths in this clay deposit. These yield envelopes are shown on Fig. 1, along with the envelope suggested by Crooks and Graham for the Holywood clay.

As already noted, a volumetric yield point occurs at an isotropic pressure in excess of $43 \mathrm{kPa}$ for the Holywood clay, so that the volumetric yield envelope of this clay probably assumes a shape as shown by the dashed line on Fig. 1, i.e. similar to the shape of the envelopes for the St Alban clay. Tavenas and Leroueil (1976) have suggested that the shape of the yield envelope of any natural clay is a function of the effective friction angle of the normally consolidated clay.

Table 1. Characteristics of the yield envelopes of 13 natural clays

\begin{tabular}{|c|c|c|c|c|c|c|c|c|c|}
\hline \multirow[t]{2}{*}{ Site } & \multirow{2}{*}{$\begin{array}{c}\text { Probable } \\
\text { deposition } \\
\text { environment }\end{array}$} & \multirow[t]{2}{*}{ Sampling } & \multirow[t]{2}{*}{ PI } & \multicolumn{2}{|l|}{$\phi^{\prime}$} & \multirow{2}{*}{$\frac{P_{\text {ver,t }_{\text {max }}}}{P_{\mathrm{c}_{\text {1so }}}}$} & \multirow{2}{*}{$\frac{P_{\mathrm{c}_{\text {oed }}}}{\boldsymbol{P}_{\mathrm{c}_{\text {iso }}}}$} & \multirow{2}{*}{$\frac{S_{\mathrm{u}_{\max }}}{P_{\text {vert }_{\max }}}$} & \multirow[t]{2}{*}{ Reference } \\
\hline & & & & $\begin{array}{l}\left(\sigma_{1}^{\prime}-\sigma_{3}^{\prime}\right)_{\max } \\
\text { unstructured }\end{array}$ & $\left(\frac{\sigma_{1}^{\prime}}{\sigma_{3}^{\prime}}\right)_{\max }$ & & & & \\
\hline Matagami & Fresh water & Blocks & 40 & & & & $2 \cdot 00$ & & $\begin{array}{c}\text { Lefèbvre } \\
\text { (1976) }\end{array}$ \\
\hline Lyndhurst & Fresh water & $\begin{array}{l}\text { NGI piston } \\
\phi 54 \mathrm{~mm}\end{array}$ & 15 & $27^{\circ}$ & $31^{\circ}$ & $1 \cdot 65$ & $1 \cdot 60$ & 0.34 & $\underset{\text { (1974) }}{\text { Graham }}$ \\
\hline Rockcliffe & Brackish water & $\begin{array}{l}\text { Osterberg } \\
\phi 127 \mathrm{~mm}\end{array}$ & 40 & & & $1 \cdot 25$ & $1 \cdot 15$ & 0.26 & $\begin{array}{c}\text { Mitchell } \\
(1970)\end{array}$ \\
\hline $\begin{array}{l}\text { Heron } \\
\text { road }\end{array}$ & Brackish water & Blocks & 36 & $27^{\circ}$ & & $1 \cdot 50$ & $1 \cdot 75$ & & $\begin{array}{l}\text { Wong and } \\
\text { Mitchell } \\
\text { (1975) }\end{array}$ \\
\hline Ottawa & Brackish water & Blocks & 40 & & & $1 \cdot 22$ & $1 \cdot 40$ & 0.25 & $\begin{array}{c}\text { McRostie et } \\
\text { al. (1972) }\end{array}$ \\
\hline St Louis & Brackish water & $\begin{array}{l}\text { Blocks } \\
+\phi 200 \mathrm{~mm}\end{array}$ & 23 & $24^{\circ}$ & & 1.53 & $1 \cdot 25$ & 0.35 & $\begin{array}{l}\text { Tavenas and } \\
\text { Leroueil } \\
\text { (1976) }\end{array}$ \\
\hline $\begin{array}{l}\text { St Alban, } \\
3.0 \mathrm{~m}\end{array}$ & Brackish water & $\phi 200 \mathrm{~mm}$ & 23 & $27^{\circ}$ & & $2 \cdot 15$ & 2.05 & $0 \cdot 34$ & $\begin{array}{l}\text { Tavenas and } \\
\text { Leroueil } \\
\text { (1976) }\end{array}$ \\
\hline $\begin{array}{l}\text { St Alban, } \\
5.7 \mathrm{~m}\end{array}$ & Brackish water & $\phi 200 \mathrm{~mm}$ & 17 & $27^{\circ}$ & & 1.85 & 1.95 & 0.32 & $\begin{array}{l}\text { Tavenas and } \\
\text { Leroueil } \\
(1976)\end{array}$ \\
\hline St Vallier & Salt water & Blocks & 37 & $24^{\circ}$ & & & $1 \cdot 50$ & & $\begin{array}{l}\text { Morin } \\
(1976)\end{array}$ \\
\hline Labrador & Salt water & Blocks & 7 & $31^{\circ}$ & & 1.40 & & $0 \cdot 19$ & $\underset{(1972)}{\text { Sangrey }}$ \\
\hline Mastemyr & Salt water & $\begin{array}{l}\text { NGI Piston } \\
\phi 95 \mathrm{~mm}\end{array}$ & 8 & $\simeq 27^{\circ}$ & $27 \cdot 5^{\circ}$ & $\simeq 1 \cdot 40$ & $\simeq 1 \cdot 20$ & 0.32 & $\begin{array}{c}\text { Graham } \\
\text { (1969) }\end{array}$ \\
\hline Drammen & Salt water & $\begin{array}{l}\text { NGI Piston } \\
\phi 95 \mathrm{~mm}\end{array}$ & 31 & & $31 \cdot 7^{\circ}$ & $1 \cdot 50$ & $1 \cdot 50$ & 0.27 & Berre (1972) \\
\hline $\begin{array}{l}\text { Holywood } \\
\text { (Belfast) }\end{array}$ & Salt water & Blocks & 22 & $26^{\circ}$ & $31^{\circ}$ & $-1 \cdot 70$ & $\simeq 1.50$ & $\simeq 0.30$ & $\begin{array}{l}\text { Crooks and } \\
\text { Graham } \\
(1976)\end{array}$ \\
\hline
\end{tabular}




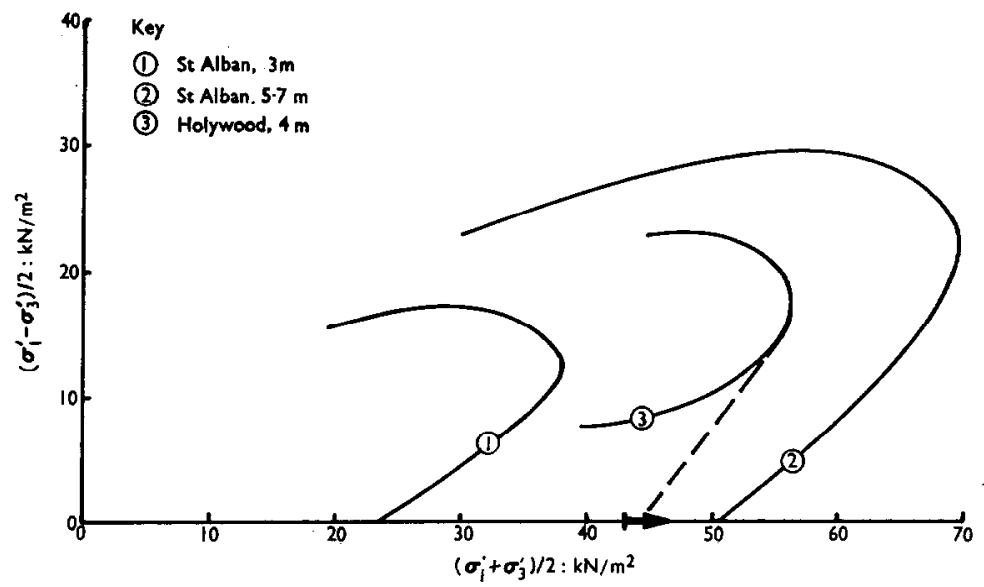

Fig. 1. Yield envelopes of the St Alban and Holywood clays

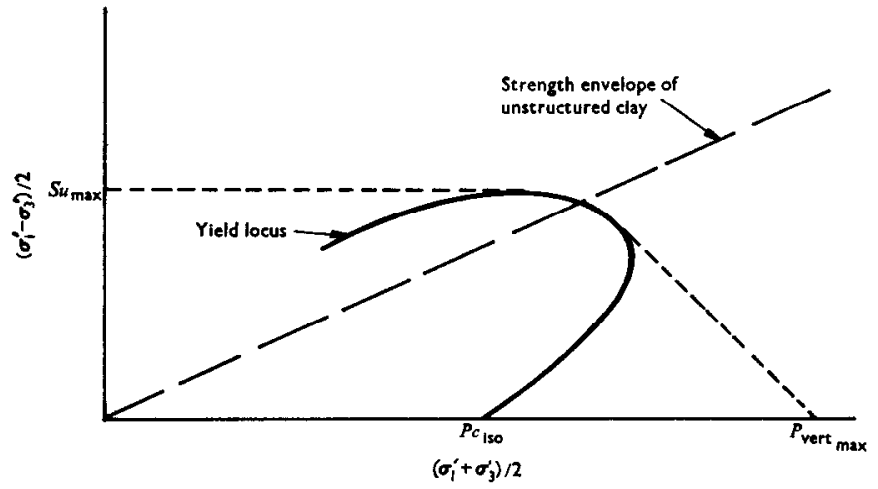

Fig. 2. Typical yield envelope and characteristic parameters

Based on the results of the CAU tests $\mathrm{C}-10$ and $\mathrm{C}-11$, and using $\left(\sigma^{\prime}{ }_{1}-\sigma^{\prime}{ }_{3}\right)_{\max }$ as failure criterion, the value of $\phi^{\prime}$ for the Holywood clay is about $26^{\circ}$, i.e. very close to the value of $27^{\circ}$ determined in a similar manner on the St Alban clay. In the conceptual model proposed by Tavenas and Leroueil (1976), two clays with the same $\phi^{\prime}$ will develop the same $K_{0}$ condition during deposition and the resulting yield envelopes, which represent the stress condition at the end of deposition, will be similar in shape. Fig. 1 seems to confirm this proposition.

\section{COMPARISON WITH OTHER YIELD ENVELOPES}

In recent years, data have been published, which allow a partial or full determination of the yield envelopes on a dozen natural clays of various origins. The direct and detailed comparison of these envelopes would be rather difficult due to the variable type and quality of data available. However, the general shape of the yield envelope of a natural clay can be represented as shown in Fig. 2 . It can be characterized by three parameters: $P_{\text {vert }}$ max , which should generally be close to $P_{\mathrm{c}}$ from oedometer tests: $P_{\mathrm{o}_{\mathrm{Iso}}}$; and $S_{\mathrm{u}_{\mathrm{max}}}$-as well as by their ratios.

Table 1 summarizes the characteristics of the yield envelopes determined on twelve natural clays from various origins and on the Holywood clay. It may first be noted that $P_{\mathrm{c}}$ and 


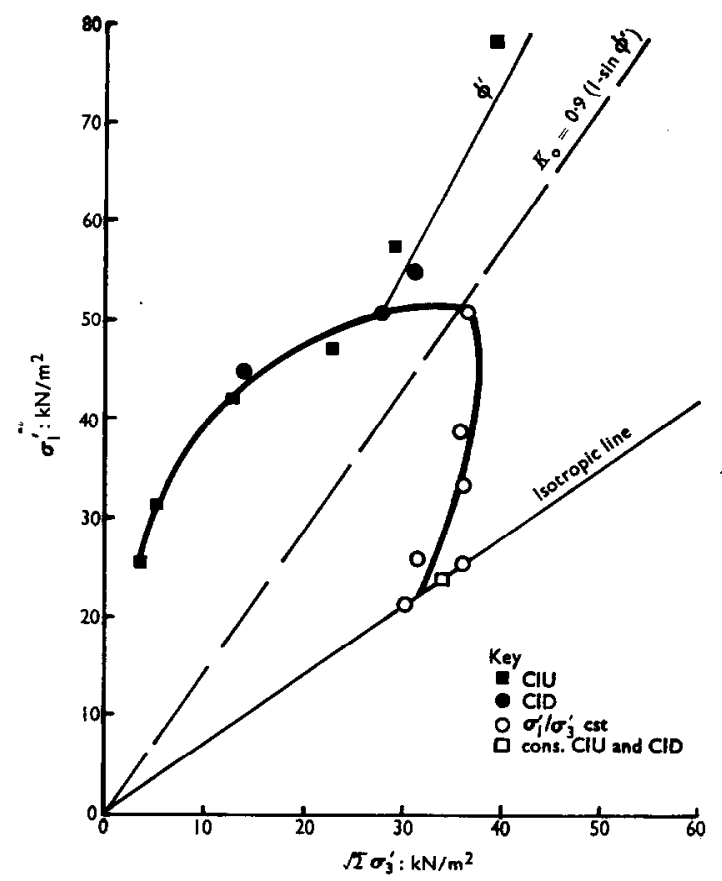

Fig. 3. True shape of the yield envelope of the St Alban clay

$P_{\text {vert }}$ max are very close to each other and would probably be equal in the absence of the usual variability of the results of tests on undisturbed samples. The analysis of the ratio of $P_{\text {vert }}$ max to $P_{\mathrm{c}_{\text {iso }}}$ leads to an important conclusion. The Cam clay and modified Cam clay models discussed by Roscoe and Burland (1968) give the equations for the theoretical shape of the yield envelope of an isotropically consolidated clay. According to these equations the maximum possible value of the ratio of $P_{\text {vert }}$ to $P_{\mathbf{c}_{\text {iso }}}$ is about $1 \cdot 18$. As shown in Table 1, the experimental value of this ratio is in excess of 1.18 for all clays, and is generally of the order of 1.4 to 1.8 . This indicates that the shapes of yield loci, and thus the constitutive equations of the Cam clay and modified Cam clay models would not be applicable to natural clays which have been deposited and consolidated under anisotropic stress conditions.

Tavenas and Leroueil (1976) suggest that the yield envelope of a natural clay is governed by the stress condition prevailing during deposition and consolidation. This stress condition has been shown to be governed by the maximum overburden pressure $P_{\text {vert }}$ max and by the coefficient of earth pressure at-rest $K_{0}=0.9\left(1-\sin \phi^{\prime}\right)$. The resulting yield envelope appears to be centred on the $K_{0}$ line in the stress space and to cross this line at $P_{\text {vert }}$ max . Consequently, for usual values of $\phi^{\prime}$ and thus of $K_{0}$, the yicld envelope will cross the isotropic line at a pressure $P_{\mathrm{c}_{\text {iso }}}$ much lower than $P_{\text {vert }_{\max }}$. The data in Table 1 confirm the general validity of this conceptual model. However, based on the shapes of yield envelopes published by some authors, it could be argued that these envelopes may not be truly centred on the $K_{0}$ stress condition. It should be noted though that a wide variety of stress space representations are used which often distort the true shape of the yield envelopes. To avoid this problem, yield envelopes should be represented in the $\sigma^{\prime}{ }_{1}, \sigma^{\prime}{ }_{2}, \sigma^{\prime}{ }_{3}$ space or in $\sigma^{\prime}{ }_{1}, \sqrt{ }^{2} \sigma^{\prime}{ }_{3}$ graphs for triaxial stress conditions, as shown in Fig. 3. Other representations such as those used by Crooks and Graham may lead to some distortion of the shape of the yield envelopes. 


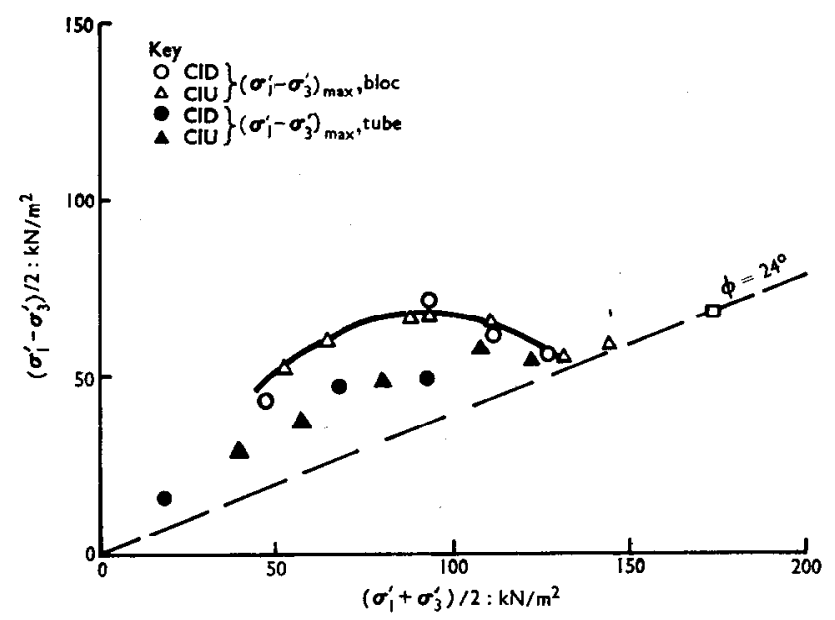

Fig. 4. Strain rate effect on the envelope of the St Louis clay

The analysis of the data presented in Table 1 hardly indicates any trend in the variations of the characteristic parameters of the yield envelopes with either the plasticity index and the friction angle or the probable deposition environment of the different clays. This should not necessarily be interpreted as a proof of the absence of any such trend. Rather, it points out the necessity, in the determination of the yield envelope of any natural clay, of considering the effects of the criteria used for determining yielding as already discussed, of the natural variability of the clay, of the sampling operations, and of the strain rates on the test results.

\section{FACTORS AFFECTING TIIE DETERMINATION OF YIELD ENVELOPES}

The proper determination of the yield envelope of a natural clay is associated with some important difficulties.

First, in order to avoid the detrimental effect of the natural variability in clay properties, it is necessary to carry out the entire test programme on large samples originating from the same depth. The use of block sampling techniques is practically mandatory. Only in this way can the clay be assumed to have been submitted to a unique geological and stress history. Common, small diameter tube or piston sampling will, on the other hand, unavoidably induce some scatter in the test results. In addition, sampling with small diameter tubes is known to induce some disturbance of the clay. Eden (1971) has demonstrated the reductions in both strengths and preconsolidation pressures caused by various tube samplers in a stiff clay from Ottawa. La Rochelle and Lefébvre (1971) have established (Fig. 4) the influence of tube sampling on the 'strength part' of the yield envelope of the St Louis clay mentioned in Table 1. More generally, by affecting the clay structure, small-diameter tube sampling can be assumed also to induce significant changes in the shape and position of the yield envelope of any natural clay.

A further problem which needs consideration in the experimental determination of the yield envelope of a natural clay, is that of strain rate effects. Based on their experimental investigation, Tavenas and Leroueil (1976) suggest that the effects of ageing and strain rates on the preconsolidation pressure of natural clays proposed by Bjerrum (1967) apply in fact to the entire yield envelope. The ageing of a clay results in a more or less homothetic displacement of its yield envelope towards higher strengths and pressures. Inversely, for an aged clay, 
a specific yield envelope exists for each possible rate of stress application. It is thus mandatory to ensure the uniformity in the rates of all tests used to determine the yield envelope of a given clay, and to evaluate the rate dependency of this envelope if it is to be used in the analysis of practical problems.

In spite of these difficulties much emphasis should be put in future on the determination of yield envelopes in as much as the concepts of yielding provide the only rational basis for the analysis of the behaviour of natural clays.

\section{Authors' reply}

We have welcomed the detailed, constructive discussion presented by Leroueil and Tavenas. It was encouraging to find their carefully argued support for the existence and importance of 'structural' effects in natural post-glacial clays. Although they questioned the detailed interpretation of some of our tests, the main thrust of the discussion was to support the concept which we mutually accept that 'yielding' of natural clays may provide the only rational basis for the analysis of many field problems.

Leroueil and Tavenas have rightly questioned the shape of the lower parts of the yield envelopes in Figs 14 and 15, and have suggested that they do not compare qualitatively with data shown in Fig. 17, or with envelopes obtained from other sites. We agree; the envelopes in Figs 14 and 15 were presented only after considerable discussion, and we intended our text to reflect this uncertainty (p. 310). Despite our experience from other sites (Graham, 1969, 1974) which agrees closely with the suggestions by Leroueil and Tavenas, we felt obliged as a result of admittedly indefinite stress-strain curves such as those shown in Figs 12 and 13, to construct the yield envelopes as published. We are uncertain about attempts to correlate CIU undrained strengths with our yield envelopes (Leroueil and Tavenas, Fig. 2). Firstly the CIU samples were consolidated isotropically and then sheared in triaxial compression, whereas we would prefer to consolidate anisotropically to about $p_{0}^{\prime}, K_{0} p_{0}^{\prime}$ and then move towards yielding along a stress path which approaches an isotropic stress state. Secondly, experience with other clays has suggested that the CIU strength may be higher or lower than CAU strengths depending on the geochemistry of the samples and the volume strains which occur during isotropic consolidation.

The suggested modifications to the yield envelopes do, however, produce closer agreement with the 'work done' contours in Fig. 19. In the absence of positive supporting evidence we suspect that the $3 \%-4 \%$ organic matter in the Belfast clays (Fig. 2) may strongly influence the small-strain behaviour of these clays. This question requires further study.

Leroueil and Tavenas have proposed that the shape of the yield envelope is a function of $\phi^{\prime}$ of the normally consolidated clay. While this is probably valid for clays which still exist in the same geochemical environment as at deposition and which have gained structural strength only through ageing, we question its general validity for clays which are cemented, highly sensitive or organic. The yield envelope is a small strain 'memory' of all the depositional, stress history, leaching and ageing processes which the clay has experienced, whereas the $\phi^{\prime}$, rupture envelope is obtained after relatively large strains and reflects only the most recent, post-sampling behaviour of that clay. Perhaps a good example of these two distinctive types of behaviour is the yield envelope shown by Mitchell (1970) for cemented Leda clay.

We note with interest the suggestion that yield envelopes become fairly sharp-nosed and symmetrical about the $K_{0}$ line, when plotted in $\sigma_{1}^{\prime}, \sqrt{2} \sigma^{\prime}{ }_{3}$ stress space.

Leroueil and Tavenas have rightly drawn attention to the need for the highest possible quality samples for determination of yield envelopes, and recommend block sampling. However, in the common case where $p_{c}^{\prime} / p_{0}^{\prime}$ varies with depth, there is also a need for good samples 
from various depths to perhaps $10 \mathrm{~m}$ depth, and the development of high quality, largediameter samplers may be needed to avoid the complexities and expense of deep block sampling.

Although the concept of yield envelopes in soft clays may initially appear difficult and esoteric, it is really only a generalization of overconsolidation as measured for example in one-dimensional consolidation and expressed by the ratio $p_{c}^{\prime} / p_{0}^{\prime}$. There is now evidence that yield envelopes do exist in many types of post-glacial clay and that they can contribute significantly to an understanding of field performances.

\section{REFERENCES}

Berre, T. (1972). Sammenheng mellom tid, deformasjoner og spenninger for normalkonsoliderte marine leirer. Proc. Nordic Conf. Soil Mech., Trondheim.

Bjerrum, L. (1967). Seventh Rankine Lecture: Engineering geology of Norwegian normally consolidated marine clays as related to settlements of buildings. Géotechnique 17, No. 2, 81-118.

Eden, W. J. (1971). Sampler trials in overconsolidated sensitive clays. Am. Soc. Test. Mat., S.T.P. 483, 132142.

Graham, J. (1969). Laboratory results from Mastemyr quick clay after reconsolidation to the in-situ stresses. Oslo: Norwegian Geotechnical Institute. Internal Report, F372-5.

Graham, J. (1974). Laboratory testing of sensitive clay from Lyndhurst, Ontario. Kingston, Ontario: Royal Military College of Canada. Civil Engineering Research Report, 74-2.

La Rochelle, P. and Lefébvre, G. (1971). Sampling disturbance in Champlain clays. Am. Soc. Test. Mat., S.T.P. 483, 143-163.

Lefèbvre, G. (1976). Private communication.

McRastie, G. C., Burn, K. N. \& Mitchell, R. J. (1972). The performance of tied-back sheet piling in clay. Can. Geot. Jnl 9, No. 2, 206-218.

Mitchell, R. J. (1970). On the yielding and mechanical strength of Leda clays. Can. Geot. Inl. 7, No. 3, 297-312.

Morin, J. P. (1976). Geotechnical behaviour of two quarternary clays from the St Lawrence Lowland. PhD thesis, Laval University, Quebec.

Roscoe, K. H. \& Burland, J. B. (1968). On the generalized stress-strain behaviour of 'wet' clay. Proc. Symp. Engineering Plasticity, Cambridge, pp. 535-610.

Sangrey, D. A. (1972). Naturally cemented sensitive soils. Géotechnique 22, No. 1, 139-152.

Tavenas, F. \& Leroueil, S. (1976). Effects of stresses and time on yielding of clays. Quebec: Laval University, Department of Civil Engineering. Internal Report GCI-76-03.

Wong, P. K. K. \& Mitchell, R. J. (1975). Yielding and plastic flow of sensitive cemented clay. Géotechnique 25, No. 4, 763-782.

\section{The influence of the membrane restraint on the measured strength of a soil sample failing along a single shear plane in the triaxial test}

PACHAKIS, M. D. (1976). Géotechnique 26, No. 1, 226-230.

Discussion by Mirata (1976). Géotechnique 26, No. 3, 539-540. Author's reply (1977). Géotechnique 27, No. 1, 102.

\section{T. Mirata, Middle East Technical University, Ankara, Turkey}

The Author in his reply to my earlier discussion has objected to my proposal to take into account the frictional properties of the soil in deriving a membrane correction; he has interpreted this as including part of the strength of the soil in the membrane correction, apparently overlooking the fact that this added strength is produced due to the restraint of the rubber membrane. 